Journal of Animal and Veterinary Advances 11 (17): 3068-3072, 2012

ISSN: $1680-5593$

(C) Medwell Journals, 2012

\title{
Serological Surveillance of Swine Influenza Virus Infection in Seven Cities Located in Guangdong Province, South China in 2010
}

\author{
${ }^{1}$ Fei-Xia Gu, ${ }^{2}$ Wen-Bao Qi, ${ }^{2}$ Shuo Su, ${ }^{2} \mathrm{Ji}$-Dang Chen, ${ }^{2} \mathrm{Hai}-\mathrm{Tao}$ Qi, ${ }^{2} \mathrm{Wan}-\mathrm{Jun} \mathrm{Zhu}$, \\ ${ }^{2}$ Zhen Huang, ${ }^{2} \mathrm{Li}-\mathrm{Kai}$ Tan and ${ }^{2} \mathrm{Gui}-$ Hong Zhang \\ ${ }^{1}$ College of Life Sciences, Zhongkai University of Agriculture and Engineering, \\ Guangzhou, 510225 Guangdong Province, China \\ ${ }^{2}$ College of Veterinary Medicine, South China Agricultural University, \\ Guangzhou, 510642 Guangdong Province, China
}

\begin{abstract}
Pigs serve as major reservoirs of H1N1 and H3N2 influenza viruses which are endemic in pig populations world-wide and are responsible for one of the most prevalent respiratory diseases in pigs. Furthermore, swine H9N2 influenza viruses might be a potential threat to human health and continuing to carry out swine influenza virus surveillance in China is of great significance. From March 2010-2011, researchers carried out serological surveillance of swine influenza in seven cities located Guangdong province in South China. The serological results indicated that antibodies to H1N1 swine influenza virus in the swine population were high with a $34.6 \%(226 / 653)$ positive rate whereas antibodies to H3N2 swine influenza virus were low with a $16.4 \%(107 / 653)$ positive rate. Antibodies to H9N2 swine influenza virus were very low with a $1.4 \%(9 / 653)$ positive rate. H1N1 influenza viruses were more dominant in the pig population than $\mathrm{H} 3 \mathrm{~N} 2$ influenza viruses in South China. H9N2 influenza virus in the pigs only send out the phenomenon in South China. According to reports in the virology and molecular epidemiological studies, the South China coastal areas of the global influenza research in key areas is the region of finding new influenza subtypes in the world and influenza outbreak. Therefore, the presence of H9N2, H1N1 and H3N2 subtypes in pigs of China and the potential public health significance have become the focus of attention of the global influenza research. After the outbreak of the flu pandemic in 2009, researchers had done a serological survey of large-scale farms in seven cities in Guangdong province. The results showed that swine influenza virus infections are more common in the surveyed farms: all farms were infected by swine influenza virus infection and more than half of the pigs present antibody-positive.
\end{abstract}

$\underline{\text { Key words: Swine influenza virus, seropervalence, Hemagglutination Inhibition (HI) assay, pig, China }}$

\section{INTRODUCTION}

Influenza type A virus is a highly infectious respiratory pathogen of different avian and mammalian species. Several subtypes of influenza type A virus have been reported based on differences in Hemagglutinin (HA) and Neuraminidase (NA) proteins. To date, $15 \mathrm{HA}$ subtypes and 9 NA subtypes have been identified in mammals and birds (Rohm et al., 1996). Pigs are considered to be mixing vessels, facilitating reassortment events among avian, swine and human influenza viruses which might allow the introduction of novel viruses into the human population (Scholtissek et al., 1985). The SIV causes acute respiratory disease in pigs and is an important pathogen in the porcine respiratory disease complex. In addition, the virus has been associated with clinical outbreaks of abortion on swine farms (Karasin et al., 2000; Zhou et al., 1999). The virus also plays an important role in the ecology and evolution of new human influenza virus strains because pigs are susceptible to infection with influenza viruses of both avian and mammalian origins (Ito et al., 1998a, b). Tracheal epithelial cells of pigs have been demonstrated to have virus receptors of 2, 3-N-acetylneuraminic acid-galactose linkages for avian influenza viruses and 2, 6-Nacetylneuraminic acid-galactose linkages for mammalian influenza viruses (Zhou et al., 1999). This dual susceptibility has implicated pigs as mixing vessels in which reassortment of human-avian influenza viruses could occur (Hughes et al., 2001; Ito et al., 1998a, b; Kida et al., 1994; Shu et al., 1994) and thus swine can act as an intermediate host for adaptation of avian influenza

Corresponding Author: Gui-Hong Zhang, College of Veterinary Medicine, South China Agricultural University, Guangzhou, 510642 Guangdong Province, China 
viruses to mammals (Castrucci et al., 1993; Kida et al., 1994; Scholtissek et al., 1985; Webster et al., 1992). The concept of a mixing vessel has been further strengthened by the fact that zoonotic transmission of SIV from pigs to humans has occurred the occurrence of the 2009 H1N1 influenza pandemic provided renewed evidence that pigs do play such a role in the influenza virus ecosystem. Since, approximately half of the world's population of do mestic pigs is farmed in China (Yao et al., 2006), this represents the largest localized collection of mixing vessels for influenza viruses in the world and therefore the greatest opportunity to generate reassortant viruses with the potential to infect humans.

Guangdong is located in Southern China, it has a great risk of influenza outbreak because of its unique geography, climate, economic and ecological conditions. At present, the pig industry specialization, scale and intensification of Guangdong province have improved greatly, however, the incidence and prevalence of swine diseases still constraint and plague swine producers. Due to their feeding large-scale, high stocking density and stress factors, it can easily cause recurring epidemics of the SI and other mass diseases, threatening to the safety of sustained and stable development of the pig industry and livestock products as well as human health. Therefore, researchers conducted the swine influenza serological surveillance in Guangdong from 2010-2011, intending to learn the overall information about the prevalence of swine influenza in South China and provide necessary data for swine influenza control and possibly also some useful information for the prediction and preparedness of future human influenza pandemi. The coexistence of ten genotype H9N2 viruses in pigs in China from 1998-2007 provides further evidence that avian to pig interspecies transmission of H9N2 viruses did occur and might result in the generation of new reassortant viruses by genetic reassortment with mammalian-adapted viruses such as swine H1N1, H1N2 and $\mathrm{H} 3 \mathrm{~N} 2$ influenza viruses, therefore, these swine H9N2 influenza viruses might be a potential threat to human health and continuing to carry out swine influenza virus surveillance in China is of great significance.

\section{MATERIALS AND METHODS}

Serum preparation: In this study, researchers selected seven large-scale pig farms in seven cities located in the Guangdong province and conducted regular inspections from September 2010-2011 to assess the prevalence of SIV. A total of 653 samples were collected from apparently healthy pigs from seven pig farms. In total, $33.38 \%$ of the evaluated samples were derived from weanling pigs, $32.77 \%$ from sows and $33.84 \%$ from grower pigs.

Hemagglutination Inhibition (HI) assay: Serological surveillance was conducted by enzyme-linked $\mathrm{HI}$ assays Sera were pretreated with a Receptor-Destroying Enzyme (RDE; Denka Seiken Co. Ltd., Tokyo, Japan) to destroy non-specific inhibitors. The serum was treated by heat inactivation at $56^{\circ} \mathrm{C}$ for $30 \mathrm{~min}$. RDE-treated sera were then absorbed with Turkey Red Blood Cells (TRBC) to remove nonspecific agglutination substances. Antibody titers were determined by testing serial 2 fold dilutions ( $1: 10$ to $1: 2560)$ of each serum in duplicate. Hemagglutination Inhibition (HI) assays were performed in 96 well microtiter plates (Corning Costar Co.) with $0.5 \%$ turkey erythrocytes using four hemagglutination units of virus. The following standard antigens were also used for HI tested: A/SWINE/GUANGDONG/3/2003 (H1N1) was chose as the standard antigen strain for the $\mathrm{Hl}$ subtype while A/SWINE/GUADONG/3/2003 (H3N2) was chose as the standard antigen strain for the $\mathrm{H} 3$ subtype and A/Swine/Guangdong/L1/2010 (H9N2) was chose as the standard antigen strain for the H9 subtype. The standard antigens were provided by the Poultry Disease Laboratory of the South China Agricultural University (Table 1).

Table 1: Serological investigation of $\mathrm{H1}$ in seven cities of Guangdong province

\begin{tabular}{|c|c|c|c|c|c|c|c|}
\hline \multirow[b]{2}{*}{ District } & \multirow[b]{2}{*}{$\begin{array}{l}\text { Quantity of } \\
\text { blood serum }\end{array}$} & \multicolumn{2}{|c|}{ H1 subtype $A b$} & \multicolumn{2}{|c|}{ H3 subtype $A b$} & \multicolumn{2}{|c|}{ H9 subtype $A b$} \\
\hline & & Positive & Percentage & Positive & Percentage & Positive & Percentage \\
\hline GuangZhou & 70 & 19 & 27.1 & 7 & 10.0 & 2 & 2.9 \\
\hline HuiZhou & 74 & 32 & 43.2 & 14 & 18.9 & 1 & 1.4 \\
\hline Zhongshan & 87 & 30 & 34.5 & 16 & 18.4 & 0 & 0.0 \\
\hline ZhanJiang & 184 & 31 & 16.8 & 21 & 11.4 & 4 & 2.2 \\
\hline JiangMen & 80 & 33 & 41.3 & 13 & 16.3 & 2 & 2.5 \\
\hline ShanTou & 80 & 47 & 58.8 & 21 & 26.3 & 0 & 0.0 \\
\hline ZhuHai & 78 & 34 & 43.6 & 15 & 19.2 & 0 & 0.0 \\
\hline Total & 653 & 226 & 34.6 & 107 & 16.4 & 9 & 1.4 \\
\hline
\end{tabular}




\section{RESULTS}

The proportion of Guangdong swine influenza serum antibody (HI) from different subtypes: In test serum, H1 subtype swine influenza antibodies showed the highest positive rate with a positive rate of between 16.8 and $58.8 \%$ in different cities and a total positive rate of $34.6 \%$ (226/653). In contrast, H3 only has a low positive rate, from $11.4-26.3 \%$ and its total positive rate was $16.4 \%$ (107/653). The antibody positive rate of H9 subtype was the lowest which was between 1.4 and $2.9 \%$ and that total positive rate was $1.4 \%(9 / 653)$.

Comparison of swine influenza serum antibody positive rate in different areas: The pig farms were tested in seven urban areas of Guangdong province in all which antibodies against $\mathrm{H} 1$ and $\mathrm{H} 3$ subtypes of swine influenza have been found with a positive rate between 11.4 and $58.8 \%$. Among them, Guangzhou, Huizhou, Jiangmen and Zhanjiang were found the presence $\mathrm{H} 9$ antibodies with a positive rate of $1.4 \sim 2.9 \%$. However, Zhongshan, Shantou and Zhuhai have not been found the infection evidence of H9 subtype influenza. The survey results show that the infection of $\mathrm{H} 1$ and $\mathrm{H} 3$ swine influenza virus is very popular in all urban areas of Guangdong province while the infection of $\mathrm{H} 9$ is sporadical without causing a pandemic.

Guangdong province is located in the Southern coastal area of China and it can be divided into four large regions, Eastern Guangdong, Western Guangdong, Northern Guangdong and Pearl River Delta region. The survey relates to the three regions, Shantou of Eastern Guangdong; Zhanjiang in Western Guangdong; Guang zhou, Jiangmen, Zhongshan, Zhuhai and Huizhou in Pearl River Delta region. Animal husbandry and aquaculture development have regional characteristics in the four regions with slightly different situation of the swine flu epidemic. The statistics test of regional distribution showed that there are large differences in subtypes of SIV antibodies situation in the three regions (Fig. 1). The swine flu antibody positive rate was 30.4, 85.0 and $56.0 \%$ in Western Guangdong, Eastern Guangdong and Pearl River Delta region, respectively.

Survey of influenza antibody at different growth stages of pigs: The results showed that in the pigs of different agepiglets have the lowest infection rate $(11.5 \%)$. To extend the feeding time, the infection rate of swine flu is getting higher and higher. The positive rate of growingfinishing pigs was $65.2 \%$, whereas that rate of breeding herd was $74.3 \%$ (Table 2 ).

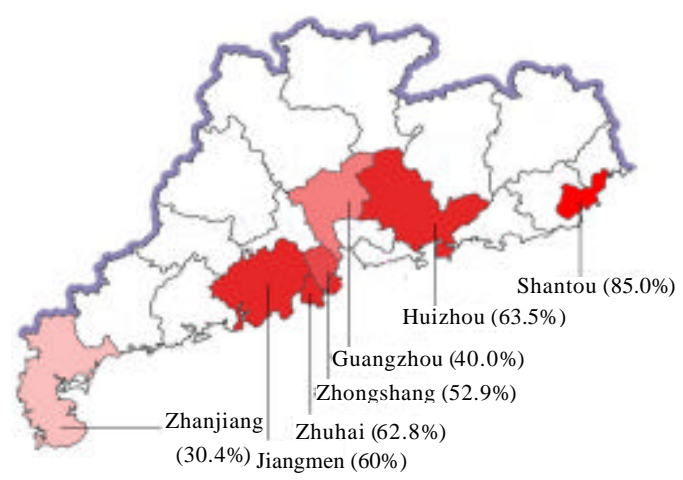

Fig. 1: Swine influenza serum antibody positive rate in different areas in Guangdong province

Table 2: Different growth stages of pigs in the Guangdong region of influenza antibody

\begin{tabular}{lccr}
\hline & Piglet & Finishing pig & \\
Project & $(2-3$ months $)$ & $(4-5$ months $)$ & Boar \\
\hline Number of pigs were detected & 218.0 & 221.0 & 214.0 \\
Number of SI-antibody positive pigs & 250.0 & 144.0 & 159.0 \\
The percent of positve (\%) & 11.5 & 65.2 & 74.3 \\
\hline
\end{tabular}

\section{DISCUSSION}

Three main subtypes of influenza viruses are currently circulating in the swine population throughout China:H1N1, H3N2 and H1N2 (Qi and Lu, 2006; Yu et al., 2007; Xu et al., 2009). In addition, antibodies to the H4, H9 influenza viruses have been detected in the Chinese swine population (Ninomiya et al., 2002) and H9 influenza viruses have been isolated and identified from pigs in China (Xu et al., 2004; Cong et al., 2007; Yu et al., 2008). Currently, infections of the swine populationin China are mainly classical H1N1 SIV whereas infection with avianlike and human origin $\mathrm{H} 1 \mathrm{~N} 1$ influenza viruses is rare. In China, avian-like swine H1N1 influenza viruses were first isolated from pigs in HongKong in 1993 (Guan et al., 1996).

According to the test results, the antibodies against $\mathrm{H} 1$ and $\mathrm{H} 3$ were confirmed in all survey farms of those seven cities of Guangdong province. It indicates the high infection level and range of swine influenza $\mathrm{H} 1$ and $\mathrm{H} 3$, consistent with previous reports. The survey also brings a warn to the latent infection state and the serious risk of swine flu in most pig farms of Guangdong province. The regional analysis revealed that the positive rate of SIV antibody is the highest in Eastern Guangdong followed by the Pearl River Delta and that of Western Guangdong is relatively low. This shows the significant regional differences in the prevalence of SIV in Guangdong. The Pearl River Delta is the pigs developed region of Guangdong province containing a higher degree of intensive pig farms and trading more frequent dealings 
with the outside world with relatively high chance of close contact with pigs infected with SIV. Western Guangdong is also another main area of feeding Guangdong pigs and its infection situation of swine flu is not to be ignored (positive rate was 30.4\%). In addition, the prevalence of the Guangdong region of SIV are likely caused by other factors such as the distribution of the different geographical environment, climatic conditions and rearing methods which should attract enough attention of the majority of farmers as well as the Animal Husbandry and Veterinary Administrative Department. Daily monitoring of swine flu is recommended to pay close attention to the swine flu epidemic dynamics and the establishment of early warning and forecasting system is essential too.

\section{CONCLUSION}

This study did serological survey of swine flu toward the scale pig herd in the urban area of seven cities of Guangdong province such as Guangzhou, Huizhou, Zhongshan and Zhanjiang while monitoring the H1, H3 and $\mathrm{H} 9$ subtypes of swine influenza antibodies the existence of conditions in pigs.

All monitored pig herd in these seven cities $(7 / 7)$ were detected the existence of $\mathrm{H1}, \mathrm{H} 3$ swine influenza antibodies. The $\mathrm{Hl}$ test for detection of SIH1 virus antibody positive rate was $34.7 \%$ and the $\mathrm{H} 3$ virus antibody positive rate was $17.7 \%$. For H9 subtype, the antibodies were found only in the pigs of four cities (4/7) and the $\mathrm{H} 9$ antibody positive rate was $1.4 \%$. The results reveal a higher detection rate of the subtypes $\mathrm{H} 1$ and $\mathrm{H} 3$, meaning a more common phenomenon of virus infection in contrast to H9. Moreover, both the antibody positive rate and antibody titer of boar were significantly higher than that in nursery pigs and growing-finishing pigs.

From the serological point of view to understand the current swine flu epidemic situation of Guangdong region, it attaches great importance to the in-depth study of the happening and the epidemic of swine flu in Guangdong province and even the whole country. It also provides the basis for the scientifically prevention and control of swine flu and the early warning for the occurring of human influenza.

\section{ACKNOWLEDGEMENT}

This study was supported by the Modern Agricultural Industry Technology System (NYCYTX009).

\section{REFERENCES}

Castrucci, M.R., I. Donatelli, L. Sidoli, G. Barigazzi, Y. Kawaoka and R.G. Webster, 1993. Genetic reassortment between avian and human influenza $\mathrm{A}$ viruses in Italian pigs. Virology, 193: 503-506.

Cong, Y.L., J. Pu, Q.F. Liu, S. Wang and G.Z. Zhang et al., 2007. Antigenic and genetic characterization of H9N2 swine influenza viruses in China. J. Gen. Virol., 88: 2035-2041.

Guan, Y., K.F. Shortridge, S. Krauss, P.H. Li, Y. Kawaoka and R.G. Webster, 1996. Emergence of avian H1N1 influenza viruses in pigs in China. J. Virol., 70: 8041-8046.

Hughes, M.T., M. McGregor, T. Suzuki, Y. Suzuki and Y. Kawaoka, 2001. Adaptation of influenza $A$ viruses to cells expressing low levels of sialic acid leads to loss of neuraminidase activity. J. Virol., 75: 3766-3770.

Ito, T., J.N. Couceiro, S. Kelm, L.G. Baum and S. Krauss et al., 1998b. Molecular basis for the generation in pigs of influenza A viruses with pandemic potential. J. Virol., 72: 7367-7373.

Ito, T., Y. Kawaoka, A. Vines, H. Ishikawa, T. Asai and H. Kida, 1998a. Continued circulation of reassortant H1N2 influenza viruses in pigs in Japan. Arch. Virol., 143: 1773-1782.

Karasin, A.I., C.W. Olsen and G.A. Anderson, 2000. Genetic characterization of an H1N2 influenza virus isolated from a pig in Indiana. J. Clin. Microbiol., 38: 2453-2456.

Kida, H., T. Ito, J. Yasuda, Y. Shimizu and C. Itakura et al., 1994. Potential for transmission of avian influenza viruses to pigs. J. Gen. Virol., 75: 2183-2188.

Ninomiya, A., A. Takda, K. Okazaki, K.F. Shortridge and H. Kida, 2002. Seroepidemiological evidence of avian $\mathrm{H} 4, \mathrm{H} 5$ and $\mathrm{H} 9$ influenza viruses transmission to pigs to South Eastern China. Vet. Microbiol., 88: 107-114.

Qi, X. and C.P. Lu, 2006. Genetic characterization of novel reassortant H1N2 influenza $A$ viruses isolated from pigs in southeastern China. Arch Virol., 151: 2289-2299.

Rohm, C., N. Zhou, J. Suss, J. Mackenzie and R.G. Webster, 1996. Characterization of a novel influenza hemagglutinin, H15: Criteria for determination of influenza a subtypes. Virology, 217: 508-516.

Scholtissek, C., H. Burger, O. Kistner and K.F. Shortridge, 1985. The nucleoprotein as a possible major factor in determining host specificity of influenza H3N2 viruses. Virology, 147: 287-294. 
Shu, L.L., Y.P. Lin, S.M. Wright, K.F. Shortridge and R.G. Webster, 1994. Evidence for interspecies transmission and reassortment of influenza A viruses in pigs in Southern China. Virology, 202: 825-833.

Webster, R.G., W.J. Bean, O.T. Gorman, T.M. Chambers and Y. Kawaoka, 1992. Evolution and ecology of influenza A viruses. Microbiol. Rev., 56: 152-179.

Xu, C., Q. Zhu, H. Yang, X. Zhang and C. Qiao et al., 2009. Two genotypes of H1N2 swine influenza viruses appeared among pigs in China. J. Clin. Virol., 46: 192-195.

Xu, C., W. Fan, R. Wei and H. Zhao, 2004. Isolation and identification of swine influenza recombinant A/Swine/Shandong/1/2003(H9N2) virus. Microbes Infec., 6: 919-925.
Yao, L., G. Li and Z. Dang, 2006. Major chemical components of poultry and livestock manures under intensive breeding. Ying Yong Sheng Tai Xue Bao, 17: 1989-1992.

Yu, H., G.H. Zhang, R.H. Hua, Q. Zhang, T.Q. Liu, M. Liao and G.Z. Tong, 2007. Isolation and genetic analysis of human origin $\mathrm{H} 1 \mathrm{~N} 1$ and $\mathrm{H} 3 \mathrm{~N}$ influenza viruses from pigs in China. Biochem. Biophys. Res. Commun., 356: 91-96.

Yu, H., R.H. Hua, T.C. Wei and Z.J. Tian, 2008. Isolation and genetic characterization of avian origin H9N2 influenza viruses from pigs in China. Vet. Microbiol., 131: 82-92.

Zhou, N.N., D.A. Senne, J.S. Landgraf, S.L. Swenson and G. Erickson et al., 1999. Genetic reassortment of avian, swine and human influenza $\mathrm{A}$ viruses in American pigs. J. Virol., 73: 8851-8856. 